\title{
EL REFUGIO POR RAZONES DE GÉNERO Gender-Based Asylum
}

\begin{abstract}
Alicia Alonso Merino ONG LEASUR, Chile

Licenciada en Derecho por la Universidad de Salamanca (España) y Abogada por el Ilustre Colegio de Abogados de Valladolid (España) con especialización en derecho de extranjería y penitenciario. Magíster sobre Migraciones Internacionales y Extranjería por la Universidad Europea en Madrid y el Consejo General de la Abogacía Española. Máster en Estudios Europeos y Derechos Humanos de la Universidad Pontificia de Salamanca (España). Diplomada en Estudios de Género por el Centro de Estudios de Género de la Facultad de Filosofía y Humanidades de la Universidad de Chile. En la actualidad es Directora de la ONG LEASUR (Chile). aliciaalonsomerino@gmail.com
\end{abstract}

\section{Nadia Silhi Chahin}

Universidad de Chile, Chile

Abogada. Licenciada en Ciencias Jurídicas y Sociales, Universidad de Chile. Diplomada en Cultura Árabe e Islámica y en Estudios Palestinos, Centro de Estudios Árabes, Universidad de Chile. nadia.silhi.chahin@ gmail.com

\section{RESUMEN}

Los presupuestos clásicos sobre los cuales se construyó el derecho de los refugiados han sido puestos a prueba por la irrupción de las solicitudes de asilo de mujeres que huyen de sus países por persecución por motivos de género. El propósito del presente trabajo es comprobar hasta qué punto esta realidad ha sido incorporada a la normativa internacional y nacional y cuáles han sido los elementos de interpretación de la misma, mediante el análisis de los instrumentos jurídicos fundantes del derecho internacional de los refugiados, como son la Convención sobre el Estatuto de los Refugiados (1951), el Protocolo sobre el Estatuto de los Refugiados (1967) y, asimismo, de la legislación chilena. De este análisis comprobamos que, ante la falta de reconocimiento inicial de la persecución por motivos de género, esta ha sido paulatinamente implementada en las directrices internacionales y en los ordenamientos jurídicos internos por vía de sus leyes de refugio, como es el caso de Chile.

\section{Palabras clave}

Refugiados; persecución; género.

\section{Abstract}

The traditional principles on which the right of refugees is based have undergone a significant transformation due, in no small measure, to the asylum claims presented by women fleeing their countries as a result of gender-based persecution. The purpose of this paper is to discuss the extent to which this reality has been incorporated into national and international legislation, the interpretations that have followed, and to analyse some of the foundational legal instruments of the Refugee Law such as the 1951 United Nations Convention Relating to the Status of Refugees and the 1967 Protocol Relating to the Status of Refugees, as well as Chilean legislation. From 
this analysis, we gather that, in the absence of initial recognition of persecution on grounds of gender, this has been gradually implemented in international guidelines and internal legal systems via their refugee Laws, as in the case of Chile.

\section{KEY WORDS}

Refugees; persecution; gender.

\section{INTRODUCCIÓN}

El 2015 se ha destacado por el aumento y agravamiento de la situación de las personas desplazadas, lo que la prensa internacional ha denominado la "crisis de los refugiados"1. Según datos del Alto Comisionado de las Naciones Unidas para los refugiados (ACNUR ${ }^{2}$, casi 60 millones de personas en el mundo son refugiadas, solicitantes de asilo o desplazadas internas. La crisis de Siria ha desplazado a casi 12 millones de personas. A 4,5 millones de ellas, a los países circundantes a Siria. Cerca de 1 millón de personas han llegado a Europa -vía Grecia, España, Italia y Malta-, más de 3.700 han fallecido o desaparecido durante el trayecto en 2015 y alrededor de 400 en lo que va de $2016^{3}$. El Mediterráneo se está convirtiendo en la tumba anónima de miles de personas que huyen de sus hogares en busca de mejores condiciones de vida.

La persecución por motivos de género se refiere al conjunto de solicitudes de refugio en las cuales el género representa una variable relevante en la determinación de la condición de persona refugiada. A pesar de la ausencia del reconocimiento expreso del género en la Convención de 1951, existen desarrollos destinados a concretar una protección efectiva de las mujeres que demandan refugio por dicha razón ${ }^{4}$, y avances que son reflejo de una toma de conciencia a nivel internacional de las violaciones de derechos humanos experimentadas por las mujeres y niñas. Para Wallace y Martín Ortega, "los derechos de las mujeres y los niños han sido tradicionalmente considerados como privados, por lo que excluían la intervención estatal. Dicha consideración no se ha limitado a la esfera internacional, sino que esta ha sido la postura generalizada, hasta hace poco, de los ordenamientos internos de muchos Estados, como pone de manifiesto, por ejemplo, la reticencia de las autoridades públicas a intervenir en los asuntos de violencia doméstica"5.

Pese a las lagunas que se mantienen en la protección de los derechos de las mujeres solicitantes de refugio y la invisibilidad de sus especificidades, se han dado en diferentes

1 Este término es frecuentemente utilizado por la prensa. Por ejemplo, los diarios El País (España) y Folha de São Paulo (Brasil) tienen una sección permanente dedicada específicamente a la "Crisis de los Refugiados"; The Telegraph (Reino Unido) se refiere a refugee crisis cuando se habla de Siria en sus noticias.

2 ACNUR (2015). Boletín Refugiados, No 3, p. 6. Disponible en: <http://www.eacnur.or g/sites/default/files/ publicacion_fichero/boletinrefugiados_noviembre2015.pdf $>$ [consulta: 15.03.2016].

3 ACNUR (2016). Boletín Refugiados, N ${ }^{o}$ 1, pp. 2-4. Disponible en: <http://www.eacnur.org/sites/default/ files/publicacion_fichero/boletinrefugiados_marzo2016.pdf $>$ [consulta: 24.05.2016].

4 ACNUR, 2002: 3.

5 Wallace, Rebeca y Martín Ortega, Olga (2004). La perspectiva de género en los procesos de concesión del estatuto de refugiada en Derecho Internacional. Revista Ámbitos (11): 89. 
legislaciones pasos significativos que, junto con las principales causas y formas de persecución, serán nuestro objeto de análisis y crítica.

En el presente trabajo analizaremos en detalle cuáles son los elementos de la interpretación de la persecución por motivos de género recogidos en la normativa internacional y las Directrices de ACNUR de 2002, además de analizar qué reconocimientos y retos plantea la actual normativa chilena en este campo.

\section{REFUGIO Y GÉNERO}

En el presente trabajo utilizaremos el concepto de "refugiado" en los términos sindicados por el artículo 1.2.A de la Convención sobre el Estatuto de los Refugiados de 28 de julio de 1951, también conocida como la Convención de Ginebra, y en el Protocolo sobre el Estatuto de los Refugiados de 31 de enero de 1967, conocido como Protocolo de Nueva York, que establecen que persona refugiada es:
"Aquella que, debido a fundados temores de ser perseguida por motivos de raza, religión, nacionalidad, pertenencia a determinado grupo social u opiniones políticas, se encuentre fuera del país de su nacionalidad y no pueda o, a causa de dichos temores, no quiera acogerse a la protección de tal país; o que, careciendo de nacionalidad y hallándose, a consecuencia de tales acontecimientos, fuera del país donde antes tuviera su residencia habitual, no pueda o, a causa de dichos temores, no quiera regresar a él".

Los daños graves a los que se enfrentaría una persona en caso de regresar a su país de origen y que justifican su necesidad de protección son: (a) la condena a la pena de muerte o la ejecución de la misma; (b) la tortura o las penas o tratos inhumanos o degradantes; y (c) las amenazas graves e individuales contra la vida o la integridad física de un civil motivadas por una violencia indiscriminada en situaciones de conflicto armado internacional o interno.

El "género", por otra parte, se refiere a los roles, derechos y responsabilidades diferentes de los hombres y las mujeres, y a la relación entre ellos. No se refiere simplemente a las mujeres o los hombres (atributos físicos), sino a la forma en que sus cualidades, conductas e identidades se encuentran determinadas por el proceso de socialización. $\mathrm{El}$ género, de forma habitual, se asocia a la desigualdad tanto en el poder como en el acceso a las decisiones y los recursos. Las posiciones diferentes de las mujeres y los hombres se encuentran influenciados por realidades históricas, religiosas, económicas y culturales ${ }^{6}$.

Asimimo, su uso reconoce la intersección de la experiencia de discriminación y violación de los derechos humanos de la mujer en razón de su género, y también de otras relaciones de poder determinadas por su raza, etnicidad, casta, clase, edad, capacidad/ discapacidad y una multiplicidad de otros factores, entre ellos su condición de indígena ${ }^{7}$.

\footnotetext{
6 Murguialdai, Clara (2000). Voz "Género". En Armiño, K. P. (Ed.). Diccionario de Acción Humanitaria y cooperación al desarrollo. Barcelona: Icaria y Hegoa, p. 1. Disponible en: <http://www.dicc.hegoa.ehu.es/ listar/mostrar/108> [consulta: 15.03.2016].

7 CABrera Muñoz, Patricia (2011). Violencias Interseccionales. Tegucigalpa: CAWN, p. 8.
} 
Las relaciones de género (es decir, las relaciones entre hombres y mujeres) constituyen y son construidas por variadas instituciones, como la familia, los sistemas legales o el mercado; son relaciones de poder jerárquicas y tienden a poner a la mujer en desventaja. Estas jerarquías a menudo son aceptadas como "naturales", pero constituyen relaciones socialmente determinadas, basadas en factores culturales y sujetas a cambios con el tiempo. Las relaciones de género son dinámicas, se caracterizan tanto por el conflicto como por la cooperación y se encuentran mediatizadas por otros ejes de estratificación como indicábamos anteriormente, como casta, clase, capacidad física o mental, edad y estado civil, o posición al interior de la familia ${ }^{8}$.

Cuando nos referimos a "la perspectiva de género" queremos con ello indicar la manera sistemática que se utiliza para abordar los impactos diferentes del desarrollo sobre las mujeres y sobre los hombres. Esta perspectiva exige desglosar la información por sexo y entender cómo está dividido y cómo se valora el trabajo. El análisis de género debe efectuarse en todas las etapas del proceso de desarrollo; debemos preguntar siempre de qué forma afectará una actividad, decisión o plan en particular a las mujeres de manera diferente que a los hombres ${ }^{9}$.

\section{NORMATIVA INTERNACIONAL EXISTENTE}

La Convención sobre el Estatuto de los Refugiados de 1951 define quién es un refugiado y establece ciertos derechos de los refugiados, además de las obligaciones de los Estados. Fue aprobada en Ginebra por los delegados de 26 naciones en el contexto del fin de la Segunda Guerra Mundial. Es el primer instrumento verdaderamente internacional que contempla los aspectos más importantes de la vida de un refugiado. Explica algunos derechos humanos fundamentales de todo refugiado que deben ser protegidos a un nivel al menos equivalente a las libertades de las que disfrutan los extranjeros en un país determinado, y en muchos casos a las de los ciudadanos en dicho Estado. Reconoce el alcance internacional del problema de los refugiados y la necesidad de la cooperación internacional para su solución, destacando la importancia de compartir la responsabilidad entre los Estados. El Protocolo de Nueva York sobre el Estatuto de los Refugiados de 1967 excluyó la posibilidad de que se limitara geográficamente la aplicación de la Convención de 1951.

Una de las críticas más frecuente a la Convención y al Protocolo es la necesaria incorporación de una perspectiva de género, que tenga en cuenta las voces y experiencias de las mujeres, excluidas del sistema de protección de derechos. No obstante, la realidad muestra algunos riesgos que se corren si se plantea una reapertura de la Convención para su modificación, por cuanto los Estados tienden a restringir el acceso a los mismos, desvirtuando el sentido del propio derecho de los refugiados ${ }^{10}$.

8 Programa de las Naciones Unidas para el Desarrollo y Alianza de Género y Agua (s.f.). Guía de Recursos: Transversalización del Enfoque de Género en la Gestión del Agua, p. 12. Disponible en: <http://www. un.org/esa/sustdev/inter_agency/gender_water/resourceGuide_Spanish.pdf> [consulta: 15.03.2016].

9 Mujeres en zona de conflicto (s.f.). Manual de Formación de Formadores sobre la Transversalidad del Género en los ODM, p. 18. Disponible en: <http://www.fongdcam.org/manuales/genero/datos/docs/1_ ARTICULOS_Y_DOCUMENTOS_DE_REFERENCIA/E_EDUCACION_PARA_EL_DESARROLLO/ Formacion_formadores_ODM_y_genero.pdf> [consulta: 15.03.2016].

10 Merino Sancho, 2008: 2. 
Sin embargo, en mayo de 2002, el ACNUR publicó las Directrices sobre Protección Internacional: la persecución por motivos de género en el contexto del Artículo 1A (2) de la Convención de 1951 sobre el Estatuto de los Refugiados, y/o su Protocolo de 1967 con el objeto de servir de guía legal interpretativa para los Estados ${ }^{11}$.

Las Directrices de 2002 se dictaron para proteger a las mujeres que huyen por persecución por motivos de género, y además pretende ser una guía jurídica interpretativa dirigida a todos aquellos que participan en los procesos de concesión, desde los gobiernos, los juristas implicados, los responsables de la toma de decisiones y los jueces, hasta el propio personal de ACNUR encargado de la determinación de la condición de refugiado sobre el terreno. Por tanto, su objetivo principal es proporcionar una mayor sensibilidad a todos estos agentes en aquellos casos en los que pueda existir una dimensión de género en una solicitud de este tipo ${ }^{12}$.

Las Directrices de 2002 subrayan que la persecución relacionada con el género no es un término jurídico per se sino que es utilizado para referirse al conjunto de solicitudes en las cuales el género representa una variable de relevancia en la determinación de la condición de refugiada ${ }^{13}$. Ahora bien, si el término "género" se refiere a la relación entre mujeres y hombres basada en identidades construidas y definidas social o culturalmente, estatus, roles y responsabilidades que son asignados a un sexo o al otro, luego el género no es estático o innato sino que adquiere significado social y cultural a lo largo del tiempo.

Las Directrices de 2002 asumen que las solicitudes por motivo de género pueden ser presentadas tanto por mujeres como por hombres, si bien debido a determinadas formas de persecución de las que son objeto las primeras, es más probable que sea en las solicitudes de estas en las que encontremos la dimensión de género que las hace merecedoras de una especial protección. Wallace y Martín consideran que "habrá, por supuesto, instancias en las que el género de la reclamante no será relevante para el resultado de la solicitud, es decir, no todas las mujeres solicitantes sufren persecución en razón de su identidad sexo-genérica y, por lo tanto, su condición de mujer no determinará el resultado del proceso de concesión de refugio"14.

Para las autoras mencionadas, las Directrices de 2002 pretenden superar los problemas que la neutralidad de la Convención sobre Refugiados provoca en la evaluación de las solicitudes de mujeres expuestas a la violencia de género. Lo hace de dos formas: (a) ofreciendo una interpretación de la definición del estatuto de refugiado más sensible a estos casos concretos; y (b) proponiendo algunas prácticas procedimentales consideradas como prerrequisito para la apropiada evaluación de las solicitudes en las que esté implicada la persecución por motivos de género ${ }^{15}$.

Como conclusión, compartimos con Wallace y Martín, que el ACNUR exhorta a todos aquellos Estados que no lo hayan hecho ya a adoptar medidas que garanticen la

\footnotetext{
1 ACNUR, 2002: 1.

2 ACNUR, 2002: 1.

3 ACNUR, 2002: 2

14 Wallace y Martin, 2004: 92.

15 Wallace y Martin, 2004: 92.
} 
consideración de la perspectiva de género en la aplicación del derecho de refugiados y sus procedimientos. Algunos Estados cuentan con una larga tradición de incorporación de la perspectiva de género a la definición de refugiado y los procesos de concesión de su estatuto. Otros, sin embargo, están empezando ahora. Sin duda, las Directrices de ACNUR han significado un impulso importante para ello, ya que ha sido una guía legal interpretativa muy válida para todos los actores jurídicos y gubernamentales ${ }^{16}$.

\section{Elementos DE INTERPRETACión DE LA PERSECUCión POR MOTIVOS DE GÉNERO}

Según las Directrices de Género del ACNUR, la persecución por motivos de género ocurre cuando el género representa una variable relevante en la determinación de la condición de refugiado ${ }^{17}$. En este sentido, es conveniente destacar la diferencia entre sexo y género que hacíamos anteriormente. Lo que nos lleva a entender que el género no es estático ni innato, sino que a lo largo del tiempo adquiere un sentido teniendo en cuenta la cultura y la sociedad.

Si bien el género no es uno de los motivos recogidos expresamente en la Convención de Ginebra, varios Estados lo han incorporado en su legislación, como es el caso de España, que lo recoge en su artículo 6.2, párrafo 3, de la Ley $12 / 2009^{18}$, y son varios los países que han elaborado directrices por medio de las cuales se brinda una protección internacional a las mujeres solicitantes de refugio, como Estados Unidos, Australia, Irlanda, Reino Unido, Suecia, Holanda y Canadá ${ }^{19}$.

Existe persecución por motivos de género cuando los daños ocasionados o las violaciones de los derechos de una persona tienen relación con el papel que se le asigna por pertenecer a un determinado sexo, o debido a su orientación sexual, o identidad de género. Si bien las solicitudes por motivos de género pueden ser presentadas tanto por hombres como por mujeres, la mayoría son por mujeres, debido, principalmente, a la situación de desigualdad que estas padecen en numerosos Estados ${ }^{20}$.

Esta persecución por motivos de género incluye, por un lado, la persecución basada en el género y, por otro, la diferenciación de formas de persecución y de castigos en función del género. La primera se da cuando la base de la persecución está en las asignaciones de género que le son atribuidas a una persona en un determinado contexto. En este caso, la persecución no habría tenido lugar de no haber pertenecido la persona a un sexo determinado. La segunda tiene lugar cuando los mecanismos utilizados para

16 Wallace y Martin, 2004: 92.

17 ACNUR, 2002: 2.

18 Establece dicho artículo que "en función de las circunstancias imperantes en el país de origen, se incluye a las personas que huyen de sus países de origen debido a fundados temores de sufrir persecución por motivos de género y, o, edad, sin que estos aspectos por sí solos puedan dar lugar a la aplicación del presente artículo".

19 Canadá fue el primer país a nivel mundial en promulgar la Guía Solicitudes de Mujeres Refugiadas con temor a Persecuciones por motivo de Género. Estas directrices de 1993 y actualizadas en 1996 constituyen una guía internacional que otros países han adoptado en sus legislaciones internas.

20 CEAR (2010). Persecución por motivos de género y derecho de asilo: del contexto global al compromiso local. Euskadi: CEAR, p. 11 
perseguir a las mujeres son diferentes de los usados para perseguir a los hombres; es decir, el tipo de castigo depende del sexo al que pertenezca una persona ${ }^{21}$.

Además, debe existir un "temor fundado" de ser perseguida. Este hecho, que puede parecer obvio, es uno de los elementos decisivos para determinar si una persona reúne los requisitos para ser reconocida como refugiada. Es, precisamente, este temor el que va a motivar que la persona decida abandonar su país, o no quiera regresar al mismo (sur place) y busque protección en otro Estado, lo que hace que la persona se convierta en refugiada.

Para que se considere que este temor es fundado no es necesario que se demuestre que ya se ha producido la persecución, sino que existe una posibilidad razonable y creíble de que la persona pueda ser sometida a persecución en caso de que se vea obligada a retornar a su país, y ello debido a sus circunstancias concretas y a la situación en el mismo.

Por ello se considera que para realizarse esta valoración, debe tenerse en cuenta la concurrencia del elemento subjetivo, que sería la existencia de un temor de persecución, y del elemento objetivo, que sería que este temor tenga su fundamento en la situación del país de origen.

En cuanto a los "motivos de persecución", para que una persona sea reconocida como refugiada, la persecución temida tiene que estar basada en los motivos recogidos en la Convención de Ginebra y en la legislación regional, es decir, raza, religión, nacionalidad, opinión política o pertenencia a un grupo social determinado, o en la legislación interna de cada Estado.

Es importante considerar que hay ocasiones en que la persecución se produce por uno de estos motivos o por una combinación de varios de ellos, pudiendo resultar a veces difícil determinar cuál de ellos concurre o cuál es el que origina la persecución de la que se es objeto ${ }^{22}$.

Como la Convención de Ginebra no recoge la definición de raza, religión, nacionalidad, opinión política o pertenencia a un grupo social determinado, hay que tener en cuenta los distintos instrumentos internacionales, el Manual de Procedimientos y Criterios para la Determinación de la Condición de Refugiado del ACNUR, las Directrices del ACNUR, la jurisprudencia de los distintos Estados y la doctrina ${ }^{23}$.

\section{El caso de Chile}

Chile es parte tanto de la Convención de 1951 como del Protocolo de 1967. En cuanto a la normativa interna, contamos con la Ley $\mathrm{N}^{\circ} 20.430$ (publicada en 2010) y su Reglamento ${ }^{24}$. Brevemente, esta consagra una definición en los mismos términos que la Convención sobre el Estatuto de los Refugiados (1951), pero también acoge elementos

21 CEAR, 2010: 14

22 CEAR et al., 2010: 17.

23 CEAR et al., 2010: 17.

24 Decreto $\mathrm{N}^{\circ} 837$ que aprueba Reglamento de la Ley $\mathrm{N}^{\circ} 20.430$, que establece disposiciones sobre protección de refugiados. Ministerio del Interior, República de Chile, 17 de febrero de 2011. 
de la Declaración de Cartagena (1984), incorporando así a personas que huyen de situaciones generalizadas en las que su vida, integridad personal o libertad corren peligro. Se incluye a los apátridas en la definición, lo que resulta novedoso, pues Chile no ha ratificado las convenciones sobre apatridia de 1954 y 1961. Consagra asimismo el principio de no devolución ${ }^{25}$ en forma amplia y detallada, siendo complementado ello por regulación respecto de la expulsión y no sanción por ingreso clandestino y permanencia irregular; se refiere a los refugiados sur place; y establece, en los mismos términos de la Convención, las causales de exclusión, cesación, renuncia, cancelación y revocación de la condición de refugiado. Determina el procedimiento a seguir para que alguien obtenga el estatus jurídico de refugiado.

La legislación chilena incorpora la persecución por motivos de género. Así, la referida Ley $\mathrm{N}^{\circ} 20.430^{26}$, en su Capítulo V (Otros Procedimientos Especiales), dispone en el artículo 41:

"Tratamiento Especial. En el caso de personas que presentaren una solicitud y alegasen haber sido víctimas de violencia sexual o por motivos de género, se procurará que los organismos públicos competentes les presten asistencia psicológica y social entrevistas, la persona pueda sentirse segura respecto de la confidencialidad de su petición" (sic).

Asimismo, el Reglamento, en su artículo $3^{\circ}$, establece:

"Condiciones especiales. En la interpretación de cada uno de los elementos del concepto de refugiado establecido en el artículo precedente, se aplicará una perspectiva sensible al género, a la edad u otras condiciones especiales de vulnerabilidad".

Luego, en relación a la incorporación en la legislación del enfoque de género para determinar la condición de refugiado, la Ley $\mathrm{N}^{\circ}$ 20.430, en su artículo 30, dispone:

"Entrevista Individual. Aun cuando no fuesen solicitantes principales del reconocimiento de la condición de refugiado todos los miembros del grupo familiar, podrán ser entrevistados individualmente y en forma separada, a fin de garantizar que tengan la oportunidad de exponer su caso en forma independiente. Todos ellos serán debidamente informados de su derecho a presentar una solicitud en forma individual y de elegir entrevistadores e intérpretes de su mismo sexo, quienes deberán ser especialmente capacitados a fin de identificar cualquier factor cultural; religioso; de género o de índole personal, tales como la edad y el nivel educativo, que pudieran afectar su habilidad para presentar su caso".

Sin embargo, la ley chilena no contempla la orientación sexual del solicitante entre las posibles formas de discriminación arbitraria a la hora de otorgar el refugio. Esta ausencia dificulta la introducción de nuevos paradigmas en este terreno, más acordes

25 El principio de no devolución, recogido en la Convención de Ginebra sobre el Estatuto de los Refugiados de 1951, se refiere a prohibición impuesta a los Estados de la expulsión o devolución de una persona al territorio de cualquier país en el que su vida o su libertad se encuentren amenazadas, o pudiera sufrir tortura, tratos inhumanos o degradantes u otras graves transgresiones de sus derechos humanos.

26 Ley N 20.430 que establece disposiciones sobre protección de refugiados. Ministerio del Interior, República de Chile, 15 de abril de 2010. 
con el orden humanitario internacional. Sí lo contemplan México ${ }^{27}$ y Costa Rica ${ }^{28}$. Brasil ${ }^{29}$, por su parte, ha aceptado casos de reasentamiento de víctimas de persecución con fundamento en orientación sexual, ya sea reconocida o imputada. En la mayoría de los casos la decisión se basa en la existencia de disposiciones legales que penalizan conductas. Como sostiene Daniel Kanstroom ${ }^{30}$, "las peticiones de asilo basadas en cuestiones de sexualidad continúan siendo tremendamente desafiantes, a pesar del progreso alcanzado hasta ahora en el campo de los derechos humanos".

Por último, si bien existen programas coordinados desde el gobierno de Chile que de hecho cuentan con la participación de $\mathrm{ACNUR}^{31}$, hay muchos desafíos en la práctica, como la incorporación de directrices claras acerca de la aplicación de los motivos de género, la formación y sensibilización al personal encargado de la aplicación de la ley, la existencia de estadísticas desagregadas y de indicadores claros de evaluación. Grafica lo anterior lo ocurrido con una mujer de nacionalidad peruana, a quien, pese a su calidad de víctima de violencia intrafamiliar debidamente acreditada, el Departamento de Extranjería y Migración (DEM) no otorgó la residencia temporaria por haber ingresado de forma irregular al país y contar con una orden de expulsión al momento de hacer la solicitud. En este caso, el Estado incumple los compromisos internacionales asumidos en materia de no discriminación, violencia intrafamiliar y protección de los derechos humanos de la mujer, ilustrando que la administración aún pone un mayor énfasis en la protección de la seguridad nacional ${ }^{32}$.

\section{Conclusiones}

Los presupuestos sobre los cuales el derecho de los refugiados se ha construido se han visto alterados debido, en gran medida, a la irrupción de las demandas de refugio por parte de las mujeres que huyen de sus países por enfrentarse a una persecución por motivos de género o una persecución generalizada.

27 Decreto por el que se expide la Ley sobre Refugiados y Protección Complementaria y se reforman, adicionan y derogan diversas disposiciones de la Ley General de Población. Presidencia de los Estados Unidos Mexicanos, 27 de enero de 2011.

28 Reglamento de Personas Refugiadas. Presidencia de la República de Costa Rica, 28 de septiembre de 2011.

29 ACNUR (2013.). Protección de refugiados en América Latina: buenas prácticas legislativas (cap. 2 "Edad, género y diversidad"), pp. 30-32. Disponible en: <http://www.acnur.org/t3/fileadmin/Documentos/Proteccion/ Buenas_Practicas/9307.pdf?view=1> [consulta: 25.05.2016].

30 Kanstroom, Daniel (2009). "Peticiones de asilo basadas en cuestiones de sexualidad: algunas respuestas y muchas preguntas". Anuario de Derechos Humanos (5): 113.

31 Son los casos de: el programa de mujeres en riesgo, para atender a mujeres colombianas reasentadas en Chile así como a mujeres refugiadas de distintas nacionalidades; la mesa de casos vulnerables coordinada por el Departamento de Acción Social del Ministerio del Interior, promoviendo una atención desde una perspectiva de género, edad y diversidad, y la mesa intersectorial sobre la trata de personas, coordinada por el Ministerio del Interior y el Servicio Nacional de la Mujer, para brindar asesoría técnica y promover la incorporación de los estándares del Derecho Internacional de Refugiados en la protección de las víctimas y sobrevivientes de trata.

32 Universidad Diego Portales (2014). Informe Anual sobre Derechos Humanos en Chile. Santiago: Universidad Diego Portales, p. 354. 
Del análisis de la normativa encontramos que, pese al no reconocimiento inicial de persecución por motivos de género en la Convención sobre el Estatuto de los Refugiados (1951) y el Protocolo sobre el Estatuto de los Refugiados (1967), las "Directrices de ACNUR sobre Protección Internacional: La persecución por motivos de género en el contexto del Artículo 1A (2) de la Convención de 1951 sobre el Estatuto de los Refugiados, y/o su Protocolo de 1967" (2002) han sido un claro avance en la materia, convirtiéndose en una guía jurídica interpretativa para los Estados sobre esta materia y han ayudado a la interpretación de cuáles son estos motivos de persecución.

Por su parte, la normativa chilena, pese a la incorporación formal de la persecución por motivos de género en su articulado, no indica directrices claras sobre su aplicación y no contempla la orientación sexual del solicitante entre las formas de discriminación arbitraria a la hora de otorgar el refugio.

No podemos olvidar que, aunque cuando crece anualmente el número de personas en situación de refugio en el mundo, la tendencia en los países occidentales de los últimos años es la de limitar la concesión de la protección internacional, reduciéndose las cifras de solicitudes de refugio concedidas ${ }^{33}$.

A pesar de los cambios legislativos y del compromiso de los Estados con la protección por razones de género, la realidad es que existen pocos datos e indicadores que nos hagan ser optimistas respecto de la concesión de la condición de refugio por este motivo.

La protección efectiva de los derechos implica el reconocimiento de las realidades sociales y de las estructuras de poder que provocan estos actos de persecución que violan per se los derechos fundamentales. Solo si se reconsideran estos aspectos podremos hablar de un nuevo régimen del derecho de refugio, más cercano a los derechos humanos.

\section{Bibliografía}

Alto Comisionado de Naciones Unidas para los Refugiados (2015). Boletín Refugiados, $\mathrm{N}^{\mathrm{o}}$ 3. Disponible en: <http://www.eacnur.org/sites/default/files/publicacion_fichero/ boletinrefugiados_noviembre2015.pdf> [consulta: 15 de marzo de 2016].

(2013). Protección de refugiados en América Latina: buenas prácticas legislativas. Disponible en: <http://www.acnur.org/t3/fileadmin/Documentos/Proteccion/ Buenas_Practicas/9307.pdf?view=1> [consulta: 25.05.2016].

(2002). Directrices sobre Protección Internacional: La persecución por motivos de género en el contexto del Artículo 1A (2) de la Convención de 1951 sobre el Estatuto de los Refugiados, y/o su Protocolo de 1967.

Cabrera Muñoz, Patricia (2011). Violencias Interseccionales. Tegucigalpa: CAWN.

33 Según datos de ACCEM, en el Estado español durante el 2014 se denegaron 44\% de las solicitudes resueltas, cuando en el 2008 era solo $10 \%$ las denegaciones. Del total de solicitudes en la UE durante el 2014 se denegaron 45\%; en el 2012 las denegaciones fueron del 32\% (datos respecto del día mundial del refugiado del año 2015). En Chile, según datos del DEM del 2015, 51,5\% de las solicitudes son rechazadas. 
CEAR (2010). Persecución por motivos de género y derecho de asilo: del contexto global al compromiso local. Euskadi: CEAR. http://www.sinrefugio.org/genero/pdf/ Anexo_5_Doc_Marco_Estrategia_CEAR_Euskadi.pdf [consulta: 25.05.2016]

CEAR et al. (2010). Exchange for Change: Guide for an effective protection of refugee victims of gender-related persecution in Europe. http://www.france-terre-asile.org/ images/stories/publications/pdf/exchange-for-change-en.pdf [consulta: 25.03.2016].

Kanstroom, Daniel (2009). Peticiones de asilo basadas en cuestiones de sexualidad: algunas respuestas y muchas preguntas. Anuario de Derechos Humanos (5): 111-121.

Merino SAncho, Víctor M. (2008). "Derecho de asilo y género: ¿ha evolucionado el derecho de asilo?". Cuadernos Electrónicos de Filosofía del Derecho (17) (Ejemplar dedicado a: Textos del Seminario "Mutilación Genital Femenina: aplicación del derecho y desarrollo de buenas prácticas en su prevención" (Valencia, 30 y 31 de octubre de 2008)). Disponible en: <http://www.uv.es/cefd/17/merino.pdf> [consulta: 15.03.2016].

Mujeres en zona de conflicto (s.f.). Manual de Formación de Formadores sobre la Transversalidad del Género en los ODM. Disponible en: <http://www.fongdcam.org/ manuales/genero/datos/docs/1_ARTICULOS_Y_DOCUMENTOS_DE_REFERENCIA/E_ EDUCACION_PARA_EL_DESARROLLO/Formacion_formadores_ODM_y_genero. pdf> [consulta: 15.03.2016].

Murguialdai, Clara (2000). En Armiño, K.P. (Ed.). Diccionario de Acción Humanitaria y cooperación al desarrollo.Barcelona: Icaria. Voz consultada: "Género". Disponible en: <http://www.dicc.hegoa.ehu.es/listar/mostrar/108> [consulta: 15.03.2016].

Parlamento Europeo (8 de marzo de 2016). El pleno pide atención especial a las mujeres en la politica de asilo. Disponible en: <http://www.europarl.europa.eu/news/ es/news-room/20160303IPR16927/El-pleno-pide-atenci\%C3\%B3n-especial-a-lasmujeres-en-la-pol\%C3\%ADtica-de-asilo> [consulta: 15.03.2016].

Programa de las Naciones Unidas para el Desarrollo y Alianza de Género y Agua (s.f.). Guía de Recursos: Transversalización del Enfoque de Género en la Gestión del Agua. Disponible en: <http://www.un.org/esa/sustdev/inter_agency/gender_water/ resourceGuide_Spanish.pdf> [consulta: 15 de marzo de 2016].

Universidad Diego Portales (2014). Informe Anual sobre Derechos Humanos en Chile. Santiago: Universidad Diego Portales.

WALLACE, Rebeca y MarTín ORTEGA, Olga (2004). La perspectiva de género en los procesos de concesión del estatuto de refugiada en Derecho Internacional. Revista Ámbitos (11): 89-96.

\section{LEGISLACIÓN}

\section{Chile}

Decreto $\mathrm{N}^{\circ} 837$, por la cual se aprueba Reglamento de la Ley $\mathrm{N}^{\circ} 20.430$, que establece disposiciones sobre protección de refugiados. Ministerio del Interior, República de Chile, 17 de febrero de 2011.

Ley $\mathrm{N}^{\circ} 20.430$, establece disposiciones sobre protección de refugiados. Ministerio del Interior, República de Chile, 15 de abril de 2010. 
Alicia Alonso Merino y Nadia Silhi Chahin

El refugio por razones de género

\section{Costa Rica}

Reglamento de Personas Refugiadas. Presidencia de la República de Costa Rica, 28 de septiembre de 2011.

\section{España}

Ley 12/2009, de 30 de octubre de 2009, reguladora del derecho de asilo y de la protección subsidiaria.

\section{México}

Decreto por el que se expide la Ley sobre Refugiados y Protección Complementaria y se reforman, adicionan y derogan diversas disposiciones de la Ley General de Población. Presidencia de los Estados Unidos Mexicanos, 27 de enero de 2011.

\section{Unión Europea}

Directiva 2004/83/CE del Consejo de 29 de abril de 2004 por la que se establecen normas mínimas relativas a los requisitos para el reconocimiento y el estatuto de nacionales de terceros países o apátridas como refugiados o personas que necesitan otro tipo de protección internacional y al contenido de la protección concedida (DO L 304/12, 30.09.2004).

Directiva 2011/95/UE del Parlamento Europeo y del Consejo de 13 de diciembre del 2011, por la que se establecen normas relativas a los requisitos para el reconocimiento de nacionales de terceros países o apátridas como beneficiarios de protección internacional, a un estatuto uniforme para los refugiados o para las personas con derecho a protección subsidiaria y al contenido de la protección concedida (refundición) (DO L 337/9, 20.12.2011). 